\title{
Capote Recalls Being Dill
}

He teased me through the bars, had bad boy charm, words like salted buckshot.

When the appeals failed, my dear, my heart was broken.

I could hardly bear the sight of the noose on his neck.

I recall a hot day, an albino rattler just coming out of the shade

so seductive in his insinuations

the gleam of the snake's white body the muscles just under the skin

the thin cool column of flesh

and my aunt's hoe like a trapdoor rising and falling in the sunlight. 